\title{
Influence of Exogenous AHLs and Quorum Quenching AiiA Protein on the Production of Cellulase Enzyme in Marine Snow Associated Bacterium, Citrobacter freundii B1
}

\author{
Abdul Nabi Jatt ${ }^{1,2 *}$ \\ ${ }^{1}$ College of Marine Life Sciences, Ocean University of China, Qingdao (266003), China \\ ${ }^{2}$ Institute of Microbiology, University of Sindh, Jamshoro 76080, Pakistan
}

\begin{abstract}
A B S T R A C T
Quorum-sensing (QS) is a system by which microorganisms can monitor their own population density via small signalling molecules to communicate with each other. The sinking of marine snow aggregates is as an essential process for moving organic carbon source from the up-ward to down-ward in the ocean. Marine snow associated bacterial communities perform a crucial role in organic material degradation by producing extracellular hydrolytic enzymes and are considered as key components in global carbon cycle. The aim of this study was to screen marine snow associated bacterium, Citrobacter freundii B1 for the production of QS-signals particularly acyl-homoserine-lactones (AHLs) and their influence on the production of extracellular cellulase enzyme. Mainly, two different reporter strains such as Agrobacterium tumefaciens A136 and Chromobacterium violaceum CV026 were applied to confirm the production of signal molecules. The identification of signal molecules was achieved by GC-MS analysis. Intriguingly, GC-MS technique showed the presence of five different AHL-signal molecules (e.g., C-6, C-8, C-10, $\mathrm{C}-12$, and C-14) produced by $C$. freundii B1. Moreover, extracellular cellulase enzyme (exoglucanase and endoglucanase) activity was highly induced in addition to exogenous AHLs. While, both exoglucanase and endoglucanase activities were radically decreased, when the growth medium was supplemented with quorum-quenching (QQ) AiiA protein. The present study, for the first time provides evidence that the QS system via AHL molecules involved in regulating the production of two different forms of an extracellular cellulase enzyme, i.e., exoglucanase and endoglucanase in marine snow associated bacterium $C$. freundii B1. Moreover, the present study has also reported five different AHL molecules (e.g., C-6, C-8, C-10, $\mathrm{C}-12$, and $\mathrm{C}-14$ ) produced by this bacterium.
\end{abstract}

\begin{tabular}{l} 
Article Information \\
\hline Received 05 March 2020 \\
Revised 30 April 2020 \\
Accepted 05 May 2020 \\
Available online 18 March 2021 \\
Key words \\
Extracellular cellulase enzyme, \\
Marine snow, AHL, Quorum-sensing, \\
Quorum-quenching
\end{tabular}

\section{INTRODUCTION}

$\mathrm{T}$ he ocean is the vigorous reservoir in the global cycling particularly carbon cycle, playing a crucial role in extenuating the effects of global warming (Sirgenthaler and Sarmiento, 1993). Extracellular hydrolytic enzymes are the essential components of a wide range of biological processes, particularly involved in the hydrolysis of complex organic matter. Generally, heterotrophic bacterial populations are very crucial in decomposition, mineralization and recycling organic matter in the marine environments by producing extracellular hydrolytic enzymes. Extracellular enzymatic activities in bacteria are regulated by several environmental factors, ecosystem, and micro-environment and particularly by quorum-sensing (QS) systems. A large number of bacterial populations inhabiting various ecological niches, produce various types

\footnotetext{
Corresponding author: abdul.nabi@usindh.edu.pk 0030-9923/2021/0003-0827 \$ 9.00/0

Copyright 2021 Zoological Society of Pakistan
}

of extracellular hydrolytic enzymes (Jatt et al., 2015; Hmelo et al., 2011). Hydrolytic enzymes produced by bacteria found in marine environment are of potential importance in hydrolyzing particulate organic matter (POC) in the ocean (Baltar et al., 2010). Cellulose is an abundant polysaccharide of glucose residues occurring in nature (Ponnambalam et al., 2011). Cellulolysis is the biological process carried out by complex of cellulase enzymes. Cellulases are classified into different groups such as endoglucanase, exo-cellobiohydrolase and $\beta$-glucosidase (Ponnambalam et al., 2011).

Citrobacter is a Gram-negative coliform bacterialgenus, belongs to Enterobacteriaceae family. Mainly, various species of the genus Citrobacter, such as C. koseri, C. amalonaticus and $C$. freundii can utilize citrate as a sole carbon-source. C. freundii is a facultative anerobic rod shaped bacterium with approximately $1-5 \mu \mathrm{m}$ in length (Wang et al., 2000). This bacterium has been reported to be present in water, food and soil and also isolated from marine snow particles (Jatt et al., 2015). C. freundii is known as an opportunistic-pathogen bacterium and causes 
various infections. However, in natural environment this bacterium has been shown to play a role in reducing nitrate to nitrite (Puchenkoya, 1996).

The sinking of marine snow aggregates has been reported as an essential process for moving organic carbon source from the up-ward to down-ward in the ocean (Kiørboe, 2001). Marine snow associated bacterial communities perform a crucial role in organic material degradation and considered as key components in global carbon cycle. Marine snow associated bacterial populations are of high importance in production of extracellular hydrolytic enzymes, involved in degrading of complex marine aggregates (Azam and Long, 2001). It has been reported that bacterial populations associated with marine particles exhibit overproduction of extracellular hydrolytic enzymes and speculated that the free-living bacterial communities may benefit from their hyperproduction enzyme activities. Interestingly, coordination of extracellular hydrolytic enzymes production is beneficial for microbial communities inhabiting marine snow (Vetter et al., 1998). Moreover, acyl-homoserine-lactones (AHLs) based Quorum-sensing (QS) system has also been reported to enhance various hydrolytic enzymes involved in the hydrolysis of marine snow aggregates, i.e., aminopeptidase, lipase, phosphatase, chitobiase and $\alpha$ - and $\beta$-glucosidase activities (Hmelo et al., 2011). Several marine snow associated bacterial populations have been reported to possess QS mechanisms, communicating with each other via AHLs and take part in dissociation of these particles and affect carbon dioxide transferred from the atmosphere to the deep sea (Hmelo et al., 2011).

QS is an environmental sensing system by which bacteria can monitor their own population density via small signaling molecules. Microorganisms use a highly specific QS-system to communicate with each other and this communication system in many bacteria particularly Gram-negative bacterial species is mediated by several kinds of AHL-signaling molecules (Fuqua et al., 2001). Large number of bacterial phenotypes have been recorded to be controlled by AHL mediated QS systems, i.e., biofilm formation and exoprotease production in Aeromonas hydrophila, plasmid conjugation in Agrobacterium tumefaciens, exoenzyme production, biofilm formation, virulence and swarming motility in Burkholderia cenocepacia, exoenzymes, cynide and pigment carbapenem production in Chromobacterium violaceum, exopolysaccharides in Pantoea stewartii and bioluminescence production in Vibrio fischeri (Williams et al., 2007).

In this study, AHL molecules produced by $C$. freundii $\mathrm{B} 1$ were investigated by two different biosensor bacterial strains such as A136 and CV026 and were further identified by GC-MS analysis. Moreover, C. freundii B1 was screened for the production of extracellular cellulase enzyme. Furthermore, the influence of exogenous AHLsignaling molecules and QQ-AiiA protein on production of cellulase enzyme was studied in detail.

\section{MATERIALS AND METHODS}

\section{Bacterial growth and culture conditions}

C. freundii B1 was isolated from marine snow particles and was identified based on 16S rRNA gene analysis (Genbank number, KJ004601), in our previous study (Jatt et al., 2015). Principally, 2216E broth was used as the culture media for the growth of this bacterium. LBmedium (Difco-Lab) was used to grow AHL biosensor bacterial strains (i.e., Agrobacterium tumefaciens A136 and Chromobacterium violaceum CV026). Mainly, LBmedium was supplemented with specific antibiotics such as spectinomycin $50 \mu \mathrm{g} \mathrm{ml}^{-1}$, tetracycline $4.5 \mu \mathrm{g} \mathrm{ml}^{-1}$ (Jatt et al., 2015; Gram et al., 2002).

\section{Screening of $\mathrm{C}$. freundii $\mathrm{B} 1$ for $A H L$ production}

AHL production by $C$. freundii B1 was detected by A136 and CV026 bacterial reporter strains in welldiffusion bioassays. Primarily, tested bacterial strain was grown in $2216 \mathrm{E}$ broth at $28^{\circ} \mathrm{C}$ for $24-48 \mathrm{~h}$ with aeration in shaking incubator. Consequently, supernatants were separated aseptically by centrifuging culture broth at $12,000 \mathrm{rpm}\left(4^{\circ} \mathrm{C}\right)$ for $10 \mathrm{~min}$. Mainly, wells $(6 \mathrm{~mm})$ were punched in LB-agar plates seeded with A136 and CV026 biosensors. LB-agar plates seeded with A136 biosensor were further added with appropriate antibiotics and X-gal solution. Mainly, up to $60 \mu \mathrm{l}$ of the sterile supernatants along with positive (3OC6-HSL) and negative control (sterile supernatants of Staphylococcus saprophyticus LV4) were added to each well. All the inoculated agar plates were placed in incubator for $24-48 \mathrm{~h}$ at $28^{\circ} \mathrm{C}$. After incubation, the plates were read for production of purple pigmentation or blue color zones if the AHL-signaling molecules were produced by the tested bacterial strain.

\section{Extraction of AHL-signaling molecules}

Extraction of AHL-signaling molecules was achieved by growing C. freundii $\mathrm{B} 1$ in $100 \mathrm{ml}$ of $2216 \mathrm{E}$ broth medium aerobically in shaking incubator $(200 \mathrm{rpm})$ at $28^{\circ} \mathrm{C}$ for 24-48h. Subsequently, cell-free sterile supernatants were obtained by centrifugation of bacterial culture broth in sterile centrifuge tubes for $10 \mathrm{~min}$ at $12,000 \mathrm{rpm}$ with $4^{\circ} \mathrm{C}$. Finally, AHL-signaling molecules were extracted by using ethylacetate acidified with formic acid (0.1\%) (Wang et al., 2011).

Gas Chromatography-mass spectrometry (GC-MS) analysis Sterile supernatants of the bacterium $C$. freundii 
B1 extracted in ethyl acetate and the synthetic standards of AHLs (C-4, C-6, C-8, C-10, C-12 and C-14) were loaded in a $\mathrm{GC}$-system $6890 \mathrm{~N}$ interfaced to a singlequadrupole Agilent-5973 Mass-Spectrometer (Agilent Technologies). Only one $\mu \mathrm{l}$ of AHL standards and sample extract of marine associated bacterium $C$. freundii B1 was injected in splitless mode of GC-MS (Rekha et al., 2011). Subsequently, AHL signal molecules produced by C. freundii B1 bacterial strain in culture extracts were identified by comparing mass-spectra and retention times against synthetic standards.

\section{Cellulase enzyme assay}

Screening of $C$. freundii B1 for the production of extracellular cellulase enzyme was performed using enzymatic agar plate assay and the enzymatic activity was quantified by spectrophotometric method. Primarily, cellulase production was detected by growing bacterial strains on medium containing $1 \%$ carboxymethyl cellulose. After incubation at $28^{\circ} \mathrm{C}$ for 3-4 days, the hydrolysis zones around the bacterial colonies were visualized by flooding the agar plates with lugol's iodine solution for $5 \mathrm{~min}$ and rinsed with deionized water (Johnsen and Krause, 2014). Exoglucanase (avicelase) activity was investigated according to the method of Lo et al. (2009), while, the endoglucanase activity was determined as described by Nitisinprasert and Temmes (1991). The amount of enzyme in terms of units was detenmined. The single unit of enzyme was defined as the amount of enzyme that releases $1 \mu \mathrm{mol}$ of reducing sugar per minute.

\section{Impact of AHLs (exogenous) and AiiA-quorum-quenching (QQ) protein}

The impact of AHLs (exogenous) and AiiA-quorumquenching (QQ) protein on the production of enzyme cellulase in bacterium $C$. freundii B1 was inspected by culturing bacterium in broth medium (2216E). A $24 \mathrm{~h}$ old broth culture was inoculated in fresh $100 \mathrm{ml}$ of $2216 \mathrm{E}$ broth. Each broth bottle was further supplemented with AiiA-protein $(20 \mu \mathrm{M})$ and $10 \mu \mathrm{M}$ of exogenous AHLs (C-4, C-6, 3O-C6, C-8, C10 and C12) (Kastbjerg et al., 2007). Moreover, ethanol $(0.1 \%)$ was used as a control. All the broth culture bottles were incubated with shaking $(200 \mathrm{rpm})$ at $28^{\circ} \mathrm{C}$. Measurement of bacterial growth was obtained at $\mathrm{OD}_{600}$ and the supernatants were separated and stored at $-20^{\circ} \mathrm{C}$ for further process.

\section{Statistical methods}

ANOVA-Tukey's test (one-way analysis of variance) was used to analyze data for any significant differences among the values. Significance differences were analyzed at $\mathrm{P}<0.05$. The computer program SPSS 21 was used for the statistical analysis.

\section{RESULTS}

\section{Production of AHL molecules by $\mathrm{C}$. freundii $B 1$}

Screening of marine snow isolated bacterium $C$. freundii $\mathrm{B} 1$ for the production of signaling molecules using A. tumefaciens A136 and C. violaceum CV026 reporter strains, indicated positive reactions with blue color zones due to AHL induced $\beta$-galactosiadse transcription by $A$. tumefaciens A136 and purple pigmentation due to $\mathrm{AH}$ induced violacein formation by $C$. violaceum $\mathrm{CV} 026$ (Fig. $1)$.

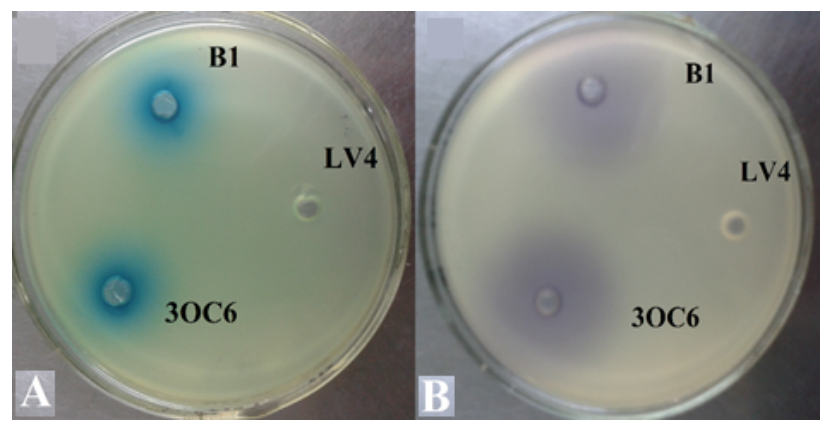

Fig. 1. Production of signaling molecules (e.g., AHLs) in sterile supernatants of $C$. fruendii B1. A shows the production of signaling molecules by A 136 biosensor and $\mathbf{B}$ indicates determination of signaling molecules by CV026 biosensor. Mainly, B1 represents sterile supernatants of the bacterial strain $C$. freundii $\mathrm{B} 1$, showing AHL production, 3OC6-HSL is a synthetic AHL represents positive control and LV4 (sterile supernatants of Staphylococcus epidermis) shows negative control in well diffusion bioassay.

Further identification of signaling AHL-molecules produced by $C$. freundii B1 was determined by GC-MS analysis, which gives a direct identification of AHLs present in the bacterial culture extracts. GC-MS analysis showed the clear peaks of the six different AHL-standards (C-4, C-6, C-8, C-10, C-12, C-14) at m/z 143 of SIM mode. All peaks of the AHL standards were observed and identified from their respective spectra. Moreover, the culture extract of $C$. freundii $\mathrm{B} 1$ produced five predominant peaks. After comparison with chromatogram created for the AHL standards, AHLs produced by $C$. freundii $\mathrm{B} 1$ were identified as C6-HSL, C8-HSL, C10-HSL, C12-HSL and C14-HSL (Fig. 2).

\section{Production of extracellular cellulase enzyme}

Extracellular hydrolytic enzyme screening assay revealed the production of cellulase by $C$. freundii B1. Cellulase enzyme was the dominant enzyme (extracellular hydrolytic) produced by this marine snow isolated bacterium (Fig. 3). 


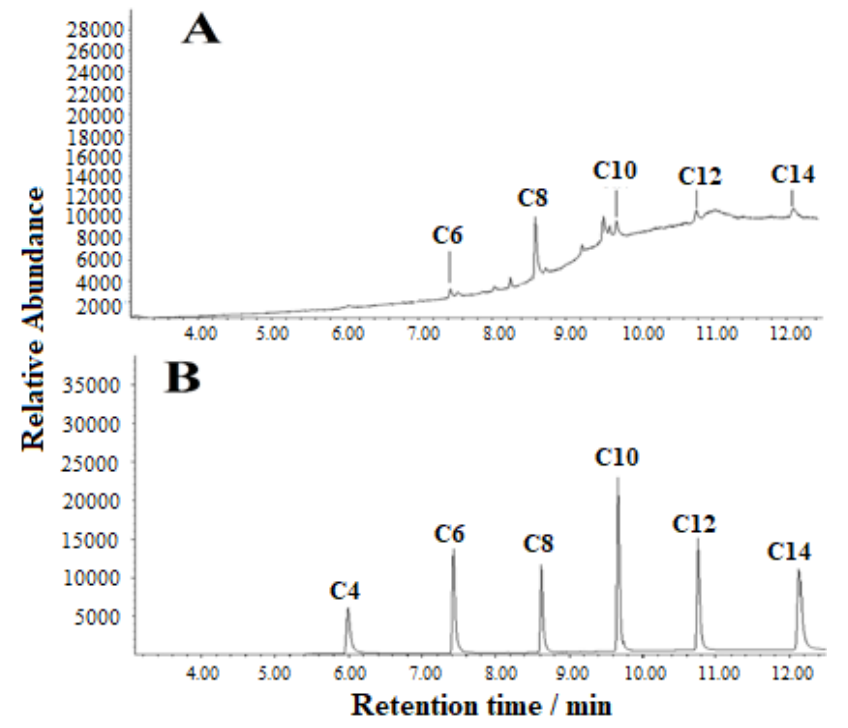

Fig. 2. Sterile culture extracts of marine snow isolated bacterium $C$. freundii B1 (A) and the mixture of six standards (synthetic AHLs) with their retention times (B) at $\mathrm{m} / \mathrm{z} 143$ in SIM mode of GC-MS.

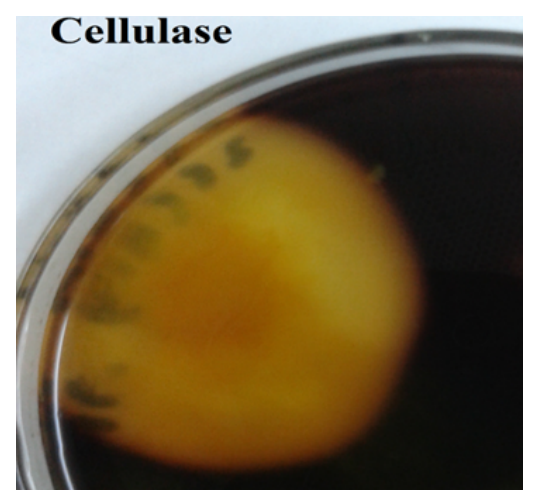

Fig. 3. Enzymatic agar plate assay showing an extracellular cellulase enzyme production by $C$. freundii B1. Mainly, agar plate was supplemented with $1 \%$ carboxymethylcellulose (CMC).

\section{Influence of exogenous AHLs and AiiA protein}

Synthetic exogenous AHL molecules (C-4, 3OC-6, C-6, C-8, C-10, C-12) added to growth medium relatively enhanced the growth of $C$. freundii B1. Moreover, the cellulolytic activity (exoglucanase and endoglucanase), was highly induced by synthetic exogenous AHL molecules. Mainly, an extremely enhanced value (557.05 $\mathrm{U} / \mathrm{ml}$ ) of exoglucanase activity was observed when the growth medium was supplemented with C8-HSL. While, an endoglucanase activity was induced $(179.85 \mathrm{U} / \mathrm{ml})$, when the growth medium was supplemented with 3OC6HSL (Fig. 4).
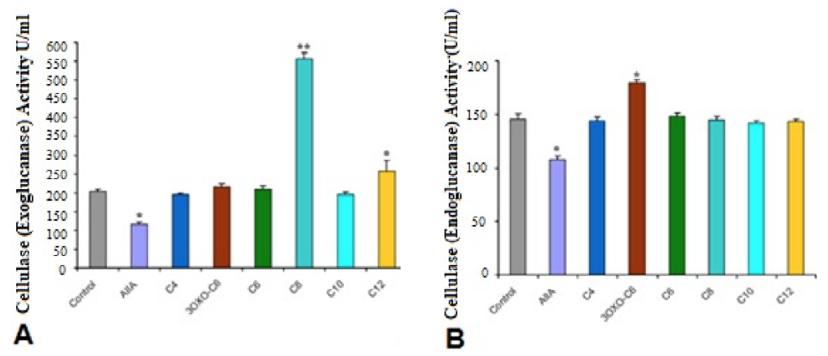

Fig. 4. Effect of signaling molecules (exogenous synthetic AHLs) and quorum-quenching (QQ) AiiA protein on an enzyme exoglucanase (A), endoglucanase (B) and the supernatants of the bacterium $C$. freundii B1. All the final results are based on means \pm SD of triplicate determinations.

The addition of QQ-AiiA protein with growth culture medium of $C$. freundii $\mathrm{B} 1$ did not show any influence on the growth rate of this bacterium. Intriguingly, QQ-AiiA enzyme highly reduced the production of the both forms of the cellulase enzyme, i.e., exoglucanase $(116.31 \mathrm{U} / \mathrm{ml})$ and endoglucanase $(107.67 \mathrm{U} / \mathrm{ml})$, as compared to control (0.1\% ethanol) (Fig. 4$)$.

\section{DISCUSSION}

Generally, large number of bacterial populations found in natural environment use AHLs to regulate a variety of phenotypes (Gonzalez and Keshayan, 2006). These AHL regulated phenotypes are crucial for beneficial or pathogenic relationship with a host. The coordinated regulation of these important phenotypes is also essential in adaptation to new modes of growth, which may support in protection from the lethal environments (Myszka and Czaczyk, 2012). Heretofore, QS system has been reported in several marine snow associated bacteria and it has also been described that QS system involves in regulation of large variety of extracellular enzymes that may involve in breakdown of particulate organic carbon (Jatt et al., 2015; Hmelo et al., 2011).

In the present study, marine snow bacterium $C$. freundii $\mathrm{B} 1$ was screened to investigate the production AHL based QS signaling molecules with the help of two different bacterial reporter strains (A. tumefaciens A136

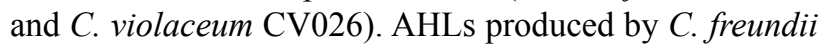
B1 were further identified by GC-MS analysis. Moreover, C. freundii $\mathrm{B} 1$ was also screened for the production of extracellular cellulase enzyme using enzymatic agar plate assay. Furthermore, the influence of exogenous AHLs and QQ-AiiA protein on the production of extracellular cellulase enzyme was studied in detail. AHL screening of C. freundii B1 indicated highly positive results for 
the production of AHL signaling molecules (Fig. 1). Intriguingly, five AHL signaling molecules were identified based on GC-MS analysis. Mainly, GC-MS analysis gives a direct identification of the AHL signals present in the bacterial culture extracts (Cataldi et al., 2007).

The enzymatic agar plate assay revealed the production of extracellular cellulase enzyme by $C$. freundii $\mathrm{B} 1$ isolated from marine snow particles. In general, bacterial communities associated with marine particles produce several types of extracellular enzymes to convert sinking POC to DOC in the marine environment. Macroscopic marine snow aggregates contribute as the principle transporter of the surface-derived organic material to the ocean interior and seafloor. Marine snow aggregates comprised of $60 \%$ of water column particulate organic carbon (Goldthwait et al., 2004). Hydrolytic activities of the bacterial exoenzymes are considered as the most important sources that perform a vital role in degradation of organic matter. Intriguingly, any process or factors that influence the extracellular enzymatic activity will impact the entire decomposition of organic matter and remineralization process and may lead to impact carbon cycle on global climate. The regulation of enzymes by QS system has been recorded in several bacterial species such as metalloprotease gene expression in Vibrio vulnificus, cell wall degrading enzymes in Erwinia carotovora, metalloprotease synthesis in Vibrio anguillarum, pectate lyases in Erwinia chrysanthemi, protease synthesis in Burkholderia cetaceans, exoprotease production in Aeromonas salmonicida, and swarming activity and extracellular protease synthesis in Serratia liquefaciens (Jatt et al., 2015; Shao and Hor, 2001).

In the present study, quantitative analysis, the extracellular cellulase (exoglucanase and endoglucanase) enzyme was highly influenced by both of the QS system via AHLs and quorum-quenching AiiA protein. Mainly, production of the both forms of the cellulase was highly enhanced in addition with exogenous AHLs. Exoglucanase activity was extremely enhanced $(557.05 \mathrm{U} / \mathrm{ml})$, when C8HSL (exogenous-AHL) was added in bacterial growth medium. While, the enhanced activity $(179.85 \mathrm{U} / \mathrm{ml})$ of endoglucanase activity was found with an addition of exogenous AHL, i.e., 3OC6-HSL (Fig. 4). Intriguingly, both of the exoglucanase and endoglucanase activities were radically decreased, when the growth medium was supplemented with quorum-quenching AiiA protein, such as $116.31 \mathrm{U} / \mathrm{ml}$ for the exoglucanase and $107.67 \mathrm{U} / \mathrm{ml}$ for the endoglucanase (Fig. 4). These results clearly indicate that the biosynthesis of the both forms of cellulase enzyme, i.e., exoglucanase and endoglucanase could be regulated by the AHL-mediated QS system. The use of AiiA protein has been considered as a reliable source for the assessment of quorum-quenching activities and has been used at large level to degrade AHL-signaling molecules without affecting growth of the bacterial species in comparison with other QS inhibitors. Mainly, the clear influence of exogenous AHLs as well as AiiA protein on the production of exoglucanase and endoglucanase activities, reveals that both of these forms of the cellulase enzyme could be regulated by AHL mediated QS system in the marine snow bacterium $C$. freundii $\mathrm{B} 1$.

Generally, cellulose is considered as one of the major carbon sources in the environment (Niranjane et al., 2007). Therefore, cellulose degradation and its subsequent utilizations are considered as an essential tool for the global carbon sources (Lakhundi et al., 2017). In natural environment the degradation of cellulose by the extracellular hydrolytic cellulase enzymes is very essential in global carbon sources. Enzymatic degradation of cellulose produces glucose, which can be employed to produce large number of organic acids, ethanol and several other chemicals. Intriguingly, cellulases are inducible enzymes produced widely by microbial populations and catalyze the function of cellulolysis.

\section{CONCLUSION}

The present study, for the first time provides evidence that the QS system via AHL molecules involved in regulating the production of two different forms of an extracellular cellulase enzyme, i.e., exoglucanase and endoglucanase in marine snow associated bacterium $C$. freundii B1. Mainly, the present study has also reported five different AHL signaling molecules such as C6-HSL, C8-HSL, C10-HSL, C12-HSL and C14-HSL produced by this bacterium. Microbial extracellular enzymes are very crucial to degrade marine aggregates that play essential role for the environment maintenance due to basic role on biogeochemical cycling and supplying nutrients which conciliates energy balance in the marine ecosystems.

\section{Statement of conflict of interest}

The authors have declared no conflict of interest.

\section{REFERENCES}

Azam, F. and Long, R.A., 2001. Sea snow microcosms. Nature, 414: 495-498. https://doi. org/10.1038/35107174

Baltar, F., Aristegui, J., Gasol, J., Sintes, E., Van Aken, H. and Herndl, G., 2010. High dissolved extracellular enzymatic activity in the deep central Atlantic Ocean. Aqua Microbiol. Ecol., 58: 287302. https://doi.org/10.3354/ame01377 
Cataldi, T. R. I., Bianco, G., Palazzo, L. and Quaranta, V., 2007. Occurrence of $N$-acyl-L-homoserine lactones in extracts of some Gram-negative bacteria evaluated by gas chromatography-mass spectrometry. Anal. Biochem., 361: 226-235. https://doi.org/10.1016/j.ab.2006.11.037

Fuqua, C., Parsek, M.R. and Greenberg, E.P., 2001. Regulation of gene expression by cell-to-cell communication. Acyl- homoserine lactone quorum sensing. Annu. Rev. Genet., 35: 439-468. https:// doi.org/10.1146/annurev.genet.35.102401.090913

Goldthwait, S., Yen, J., Brown, J. and Alldredge, A., 2004. Quantification of marine snow fragmentation by swimming euphausiids. Limnol. Oceanogr., 49: 940-952. https://doi.org/10.4319/1o.2004.49.4.0940

Gonzalez, J.E. and Keshavan, N.D., 2006. Messing with bacterial quorum sensing. Microbiol. Mol. Biol. Rev., 70: 859-875. https://doi.org/10.1128/ MMBR.00002-06

Gram, L., Grossart, H., Schlingloff, A. and Kiorboe, T., 2002. Possible quorum sensing in marine snow bacteria: Production of acylated homoserine lactones by Roseobacter strains isolated from marine snow. Appl. environ. Microbiol., 68: 41114115. https://doi.org/10.1128/AEM.68.8.41114116.2002

Hmelo, L., Mincer, T.J. and Van Mooy, B.A., 2011. Possible influence of bacterial quorum sensing on the hydrolysis of sinking particulate organic carbon in marine environments. Environ. Microbiol. Rep., 3: 682-688. https://doi.org/10.1111/j.17582229.2011.00281.x

Jatt, A.N., Tang, K., Liu, J., Zhang, Z. and Zhang, X.H., 2015. Quorum sensing in marine snow and its possible influence on production of extracellular hydrolytic enzymes in marine snow bacterium Pantoea ananatis B9. FEMS Microbiol. Ecol., 91: 1-13. https://doi.org/10.1093/femsec/ fiu 030

Johnsen, H.R. and Krause, K., 2014. Cellulase activity screening using pure carboxymethylcellulose: application to soluble cellulolytic samples and to plant tissue prints. Int. J. mol. Sci., 15: 830-838. https://doi.org/10.3390/ijms15010830

Kastbjerg, V.G, Nielsen, K.F, Dalsgaard, I., Rasch, M., Bruhn, J.B., Givskoy, M. and Gram, L., 2007. Profiling acylated homoserine lactones in Yersinia ruckeri and influence of exogenous acyl homoserine lactones and known quorumsensing inhibitors on protease production. J. appl. Microbiol., 10: 363-374. https://doi.org/10.1111/ j.1365-2672.2006.03109.x
Kiørboe, T., 2001. Formation and fate of marine snow: Small-scale processes with large-scale implications. Sci. Mar., 65: 57-71. https://doi.org/10.3989/ scimar.2001.65s 257

Lakhundi, S.S., Duedu, K.O., Cain, N., Nagy, R., Krakowiak, J. and French, C.E., 2017. Citrobacter freundii as a test platform for recombinant cellulose degradation systems. Lett. appl. Microbiol., 64: 3542. https://doi.org/10.1111/lam.12668

Lo, Y.C., Saratale, G.D., Chen, W.M., Bai, M.D. and Chang, J.S., 2009. Isolation of cellulose-hydrolytic bacteria and applications of the cellulolytic enzymes for cellulosic biohydrogen production. Enz. Microb. Tech., 44: 417-425. https://doi. org/10.1016/j.enzmictec.2009.03.002

Myszka, K. and Czaczyk, K., 2012. N-acyl homoserine lactones (AHLs) as phenotype control factors produced by Gram-negative bacteria in natural ecosystems. Polish J. environ. Stud., 21: 15-21.

Niranjane, A.P., Madhou, P. and Stevenson, T.W., 2007. The effect of carbohydrate carbon sources on the production of cellulase by Phlebia gigantea. Enz. Microb. Tech., 40: 1464-1468. https://doi. org/10.1016/j.enzmictec.2006.10.041

Nitisinprasert, S. and Temmes, A., 1991. The characteristics of new non-spore-forming cellulolytic mesophilic anaerobe strain CM126 isolated from municipal sewage sludge. J. appl. Bact., 71: 154-161. https://doi. org/10.1111/j.1365-2672.1991.tb02972.x

Ponnambalam, A.S., Deepthi, R.S. and Ghosh, A.R.., 2011. Qualitative display and measurement of enzyme activity of isolated cellulolytic bacteria. Biotech. Bioinform. Bioeng., 1: 33-37.

Puchenkova, S.G., 1996. Enterobacteria in areas of water along the Crimean coast. Microbiol. J., 58: 3-7.

Rekha, P.D., Young, C.C., and Arun, A.B., 2011. Identification of $\mathrm{N}$-acyl-L-homoserine lactones produced by non-pigmented chromobacterium aquaticum CC-SEYA- $1^{\mathrm{T}}$ and pigmented Chromobacterium subtsugae PRAA4-1 ${ }^{\mathrm{T}}$. 3 Biotech, 1: 239-245. https://doi.org/10.1007/s13205-0110029-1

Shao, C.P. and Hor, L.A., 2001. Regulation of metalloprotease gene expression in Vibrio vulnzficus by a Vibrio harveyi LuxR homologue. J. Bact., 183: 1369. https://doi.org/10.1128/JB.183.4.13691375.2001

Sirgenthaler, U. and Sarmiento, J., 1993. Atmospheric carbon dioxide and the ocean. Nature, 365: 119125. https://doi.org/10.1038/365119a0 
Vetter, Y., Deming, J., Jumars, P. and Krieger-Brockett, B., 1998. A predictive model of bacterial foraging by means of freely released extracellular enzymes. Microb. Ecol., 36: 75-92. https://doi.org/10.1007/ s002489900095

Wang, J., Quan, C., Wang, X., Zhao, P. and Fan, S., 2011. Extraction, purification and identification of bacterial signal molecules based on $N$-acyl homoserine lactones. Microb. Biotechnol., 4: $\quad 479-490$. https://doi.org/10.1111/j.17517915.2010.00197.x
Wang, J. T., Chang, S. C., Chen, Y. C. and Luh, K. T., 2000. Comparison of antimicrobial susceptibility of Citrobacter freundii isolated in two different time periods. J. Microbiol. Immuno. Infect., 33: 258-262.

Williams, P., Winzer, K., Chan, W.C. and Camara, M., 2007. Look who's talking: communication and quorum sensing in the bacterial world. Biol. Sci., 362: 1119-1134. https://doi.org/10.1098/ rstb.2007.2039 